\title{
A Novel Scheme for Teaching Diversity Skills to Students in the Technological Sector
}

\author{
Dr. Saeed M. Khan and Dr. Beverlee Kissick \\ College of Technology and Aviation \\ Kansas State University-Salina
}

\section{DIVERSITY AND INDUSTRY:}

It is now widely accepted that diversity has business implications, and that the proper handling of diversity is crucial in a global economy. Major U.S. corporations have supported the University of Michigan's pro-diversity admissions policy [1]. Intel is an example of a successful company that has had a multicultural training program [2] since 1983. Intel's program initially designed to help foreign-born technologists succeed in the American industrial environment, now includes programs that help U.S.-born workers to collaborate successfully with their non-native colleagues both here and abroad. Both the Technology Accreditation Commission (TAC) and the Engineering Accreditation Commission (EAC) of the Accreditation Board for Engineering and Technology (ABET) have recommended that all programs seeking ABET accreditation pay serious attention to teaching and assessing diversity skills $[3,4]$. Drs. Kissick and Khan have been involved in studying and developing schemes to promote diversity at the College of Technology and Aviation at Kansas State University-Salina [5-7], and believe that this can best be accomplished by teaching some simple rules that foster diversity friendliness and teach good business practices. It was important for the authors that the rules and their impact on business be easily understood. There should not be too many rules and they should have an expansive reach through logical extension. We hope to facilitate students' ability to make rational decisions in a manner consistent with game theory, which assumes that people "act in their own self interest," and are able to determine "at least probabilistically, the outcomes of their actions, and have preferences over these outcomes [8]." According to game theory, an optimal solution to any problem involving interdependent individuals has among its basic requirements that the individuals should be acting rationally (as defined above). The authors believe that students would be best prepared to handle diversity in industry if they were taught to apply rational decision making rules to multicultural issues in the workplace. We begin by talking about the rules of diversity (what we are interested in teaching) and will follow this up with a description of our chosen mechanism of delivery (a novel survey). Before concluding, we will discuss the survey results from two separate settings, a multicultural meeting and an ASEE regional conference presentation.

\footnotetext{
"Proceedings of the 2005 American Society of Engineering Education Conference \& Exposition Copyright (C) 2005, American Society of Engineering Education"”
} 


\section{THE RULES OF DIVERSITY:}

What is it that we wish to teach regarding diversity? For the answer to this question we will refer to Yee's definition of diversity [7] and multicultural competencies defined by the Tilford Group [9]. Yee addresses four different levels of concern. The areas of concern identified were as follows: (1) personal level (how do I feel about those who are different?); (2) interpersonal level (how do I behave with regard to people who are different?); (3) institutional and organizational level (what are the politics, treatment, behavior, procedures, and policies toward different groups of people?); and (4) cultural or societal level (how do we broaden our view of what is right and good?). The set of competencies as defined by the Tilford Group include the three broad areas of knowledge, personal attributes, and skills (with many subcategories in each area). In a previous paper [10] the authors have shown both systems of classification to be fairly comprehensive and therefore either one can serve as a basis for our rules. Any rule presented should meet the following criteria,

a) All rules should be inferred from expert advice, statistically relevant facts or empirical evidence;

b) Each rule will be presented with an example of how it is applied in making a business decision;

c) All rules taken together must comprehensively satisfy all requirements in any accepted definition of diversity skills (e.g. Yee's four levels of concern, multicultural competencies, etc.).

\section{DEVELOPING A SCHEME:}

We wanted our students to realize what diversity issues might come up in the industrial workplace. How could we do this in a classroom setting? We hoped classroom of students could actually function as a focus group, we created a survey that could builds awareness, and encourages our students to question the situations housed in our survey. We thought this was a good beginning. Webster [11] defines a survey as a "detailed study or inspection, as by gathering information through observations, questionnaires, etc. and analyzing it." Webster also defines literature as "such writings considered as having permanent value, excellence of form, great emotional effect". We wanted our survey questions to include the characteristics that classic literature encompass. We knew questions involved with diversity would normally be given a sensitive status. All of our families have traditional stories, beliefs, customs handed down to us. They are difficult to displace and sometimes prejudicial. Controversy is a part of creativity. We accept that.

\section{THE SURVEY:}

Fig. 1 below is a diagrammatic representation [12] of our scheme. First a "statement" is

\footnotetext{
"Proceedings of the 2005 American Society of Engineering Education Conference \& Exposition Copyright (C) 2005, American Society of Engineering Education”
} 


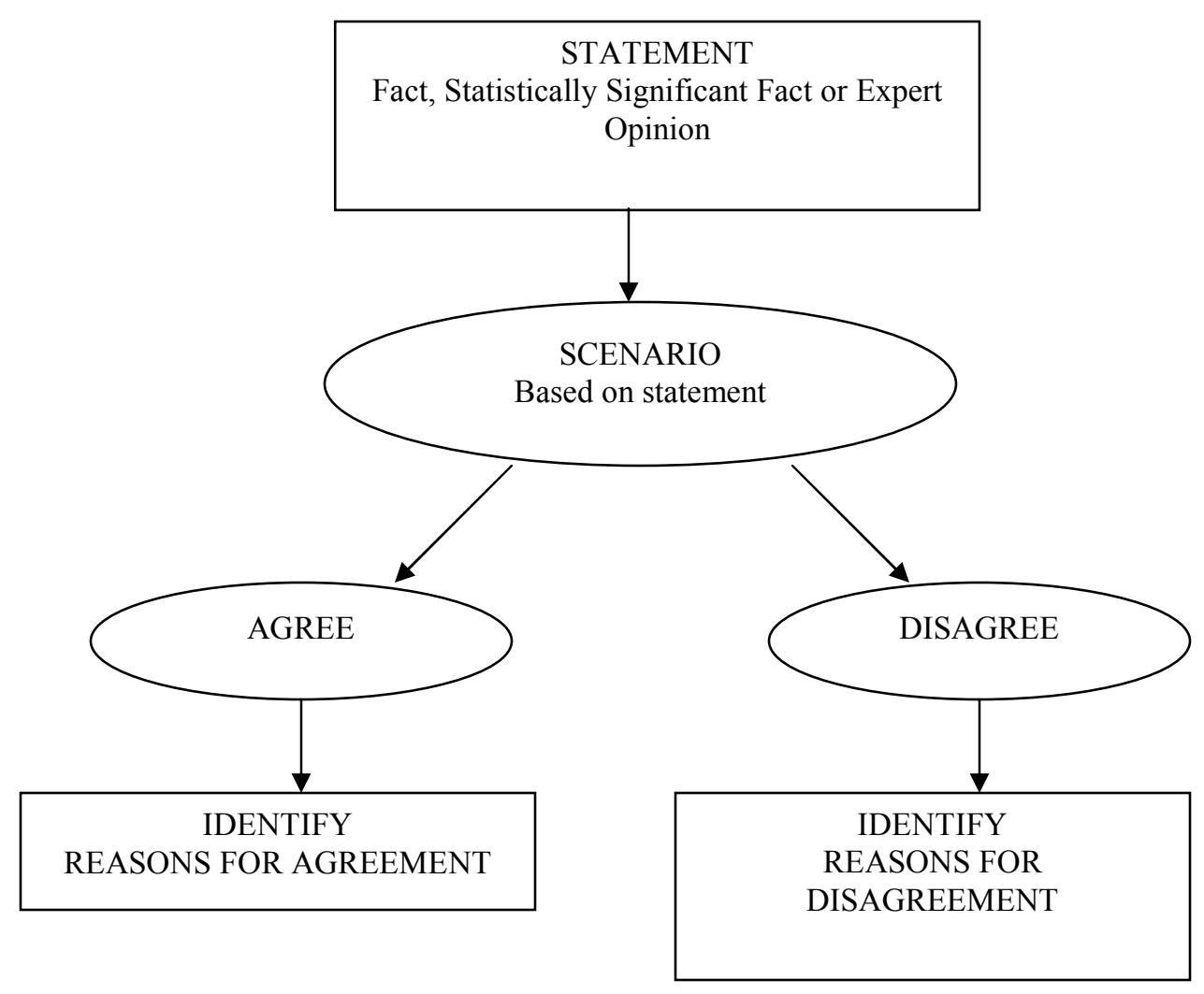

Fig. 1. The Survey Scheme

made regarding some diversity issue. The statement is solidly supported by statistical data, by a statement of fact or by an expert opinion. Following the "statement" a "scenario" is cooked up. This scenario will usually describe a situation which calls for judgement to be made based on the information contained in the statement (A logical extrapolation of the facts or knowledge provided). Students taking the survey are then asked as to whether or not they agree with the judgment provided in the scenario. If the person taking the survey ends up agreeing, we then try to identify his or her reasoning through a second multiple-choice question. If more than one choice applies, we will ask the person to select the most important consideration. If the person taking the survey disagrees with the decision, we will then seek to find the reasons for disagreement.

\section{WHAT THE SURVEY ACCOMPLISHES:}

The survey accomplishes the three things listed below,

I. It informs the surveyed with important facts, statistics or expert opinions about diversity issues. A simple statement concerning bilingual people in Table 1, for instance, can be very illuminating to those who carry a negative image of this group. People may find the only rational response to this tidbit of knowledge is to get rid of the some harmful stereotype that they have clung to in the past. On the other hand, the bias may be so deep that they may dismiss the statement as outright propaganda, in which case this activity fails to impact the level of 
diversity friendliness of such individuals. It does however (upon further probing) tell us why such individuals could not believe this information.

The selection of the "tidbit" of diversity information needs to be done with care as any random statement (however solidly grounded in fact, statistics or expert opinion) will not further the diversity cause. The authors chose an example that will show the bilingual background as an asset (for those who may not know). The importance of the statement above cannot be undersold in a society where a significant portion is bilingual. Many other such high-impact positive "statements" can be converted into survey questions that promote diversity, such as statements concerning skin color, national origin, culture, etc.

II. If one accepts this information and agrees with the rational extrapolation of this info, we can then identify the reasons with the second question (why do they agree?). This question is just as important as the first and it tells us why someone may choose to agree or strongly agree with the rational application of the statement (i.e. the "scenario"). These reasons will be useful information for those who are searching for more effective ways to promote diversity.

III. If one disagrees with the information, their reasons for disagreement can be identified through another multiple choice question. This allows diversity promoters to further enhance their diversity program by trying to get rid of these misconceptions.

\section{TABLE 1.}

Statement

There is empirical evidence that bilingual people are more creative and productive on average.

Scenario

Two candidates have been interviewed for the same position. Both candidates are equally qualified for the job.

\section{Action based on}

statement

The bilingual person is hired.

1. Do you agree with the decision to hire the bilingual person?
A. Strongly
B. Agree
C. Disagree
D. Strongly

Agree disagree

2. If your answer to question number 1 is $\mathrm{A}$ or $\mathrm{B}$, why do you agree?

(Select the best answer)

A. The hiring decision is good for business.

B. It is the ethical thing to do.

C. It helps bilingual people.

D. It makes up for past inequities.

3. If your answer to question number 1 is $\mathrm{C}$ or $\mathrm{D}$, why do you disagree?

A. The hiring decision could be bad for business.

B. This decision is bad for my race.

C. It will force us to pick a candidate with whom we may not be comfortable

D. It is designed to make up for past inequities. 


\section{OFFERING THE SURVEY:}

We offered our sample survey question (in table 1) to two groups with different levels of diversity experience. The first group consisted of attendees at an ASEE (American Society of Engineering Education) regional conference; and the second comprised of the Tilford Group, a set of educators charged with developing a multicultural curriculum at K-State. The ASEE group, numbering approximately twenty were predominantly teachers associated with engineering and technology colleges, when we administered the survey to this group, four or five readily responded by saying that they agreed with the decision in the scenario. This was obviously the rational response that we expected most people to make based on the premise built into the scenario.

One member of the ASEE group wondered why we were guiding the selection of the answers. He seemed to be satisfied when we reminded him that our intention was to solicit a rational response while trying to expose people to some positive statements regarding bilingual people.

Two members of the ASEE group were unhappy about our scenario. One of them countered by asking us what we would do if it turned out that white men were harder working than any other group. At one level we found this reaction particularly interesting since we did verbally state that the decision to hire the bilingual candidate was made based on the fact that the two candidates were equal in all other aspects. On closer examination too, the statement that white men could be harder working as a group is irrelevant to our survey, for both candidates could have been white men. It was not our intention to compare the merits of hiring different racial groups. Our second detractor pointed out the problems some bilingual and bicultural people have in adjusting to an American workplace (an assertion that fails to note the candidates were equal in all other aspects, once again). Surprisingly, no one made any comments about the statement itself. The scenario, however is one in which we do accept the statement as the foundation for our decision. While the survey statement was based on 24 studies that have shown a positive correlation between creativity and bilingual aptitude [13], such a relationship is by no means universally accepted at the present time, and therefore could be open to challenges in this format.

We next administered the survey to a meeting of the Tilford Group at KSU. Members responded without hesitation by selecting the rational choices. After the survey was completed, there was some discussion regarding the statement and choices. One person pointed out to us that there was stronger evidence suggesting that bilingual and bicultural people were more creative than others. Another Tilford Group member suggested that the race of the job candidates in the scenario might also be a significant factor in decision making. While we agree that race could indeed influence the answers, we thought it best to leave it colorblind and minimize the factors in the decision making scheme. 


\section{SUMMARY:}

In this paper, we discussed the design and development of a novel survey scheme to promote diversity. Our survey begins with a positive statement about diversity and creates a scenario in which respondents can draw on the statement to make a hypothetical decision concerning hiring. Rational responses to this survey are then solicited, as to whether or not people agree with the decision made. A single survey question was run for two different groups of people. The first group (attendees at an ASEE conference) was less conversant with diversity issues, and had a more difficult time in dealing with questions posed. The second group, being well-versed in diversity issues, hesitated very little while completing the survey. In both cases, we felt that the resulting discussion had been useful in sparking a dialogue. We feel that any dialogue on diversity is an intrinsic part of its promotion, whether the goal is world peace or, in this case, simply business methods.

\section{REFERENCES:}

1. Berman, L., "Big business is on U-M's side as diversity battle plays in courts", The Detroit News, January 21, 2003

2. Sharon Richards, "Diversity in the high-tech workplace: making engineers feel at home." IEEE Spectrum, Vol. 29, June 1992, pages 29-30

3. Technology Accreditation Commission of the Accreditation Board for Engineering and Technology (TAC of ABET) website. http://www.abet.org/tac1.html

4. Engineering Accreditation Commission of the Accreditation Board for Engineering and Technology (EAC of ABET) website. http://www.abet.org/eac1.html

5. Saeed Khan, "Teaching Diversity at the College of Aviation and Technology," Conference Proceeding of the $33^{\text {rd }}$ ASEE/IEEE Frontiers in Education Conference, November 5-8, 2003, Boulder, CO, pages F3D-24 to F3D-28

6. Beverlee Kissick and Saeed Khan, "Expectations: Leadership, Dialogue and a Long-Term Commitment to diversity promotion," Conference Proceeding of the $38^{\text {th }}$ ASEE Midwest Section Meeting, Sept. 10-12, Rolla, MO, 9 pages

7. Beverlee Kissick and Saeed Khan, "Expectations: Leadership, Dialogue and a continuing commitment to Diversity Promotion," Conference Proceedings ASEE 2004 National Conference at Salt Lake City, UT, June 2004, 9 pages

8. Graham Romp, Game Theory: Introduction and Applications, Oxford University Press, 1997, pages 2-3

9. Yee, D., "Introduction: recognizing diversity, moving toward cultural competence." Generations (San Francisco, Calif.), 26(3), 2002

10. McGown, J. (2002). Multicultural competency development: preparing students to live and work in a diverse world. Retrieved May 082003 http://www.ksu.edu/catl/tilford/Competencies.htm

11. Webster's' New World College Dictionary, Fourth edition, Michael Agnes, Editor, 1992, Macmillan, p1442

12. Saeed Khan and Beverlee Kissick, "The Design of a Knowledge Based Survey Scheme for Quantifying and Propagating Diversity Skills in Science and Technology," Proceedings of the 2004 American Society of Engineering Education Midwest Section Conference, Pittsburg, Kansas, October 2004, 5 pages

13. Ricciardelli, L.A., Creativity and bilingualism, Journal of Creative Behaviour, Volume 26, Issue 4 The Journal, Creative Education Foundation, Buffalo, New York, 1992, pp242-254 
Saeed Khan is an Associate Professor with the Electronic and Computer Engineering Technology program at Kansas State University at Salina. Dr. Khan received his Ph.D. and M.S. degrees in Electrical Engineering from the University of Connecticut, in 1989 and 1994 respectively. He received his B.S. in Electrical Engineering from Bangladesh University of Engineering and Technology, Dhaka, Bangladesh in 1984. Khan, who joined KSU in 1998, teaches courses in telecommunications and digital systems. His research interests and areas of expertise include antennas and propagation, novel materials for microwave application, and electromagnetic scattering. Dr. Khan is a member diversity committee at the College of Technology and Aviation, and also serves as a member of Tilford Group, a research and development group charged with creating a multicultural curriculum model.

Beverlee Kissick earned three degrees from Kansas State University at Manhattan, Kansas: a B.S. in Sociology, MS in Curriculum and Instruction, and a Ph.D. in Educational Technology Library/Media. Beverlee is a Professor and Director of Libraries at Kansas State University at Salina where she has taught sociology. Beverlee taught at Virginia Commonwealth University, Richmond, Virginia, Fort Hays State University, Hays, Kansas, and in Kansas public schools. Kissick chaired the diversity committee at KSU at Salina for three years and has served on the President's Council on Multicultural Affairs and the Tilford Group at Kansas State University at Manhattan. Beverlee is known for her presentations on Practical Humanities. 